Supporting information for

\title{
Facile Removal of Phytochromes and Efficient Recovery of Pesticides Using Heteropore Covalent Organic Framework- Based Magnetic Nanospheres and Electrospun Films
}

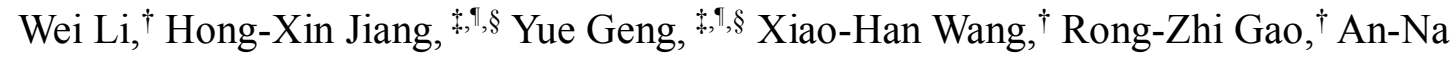
Tang, ${ }^{\dagger}$ De-Ming Kong ${ }^{*} \dagger$

†Tianjin Key Laboratory of Biosensing and Molecular Recognition, Key Laboratory of Functional Polymer Materials, Ministry of Education, College of Chemistry, Nankai University, Tianjin, 300071, People's Republic of China

*Agro-Environmental Protection Institute, Ministry of Agriculture, Tianjin, 300191, People's Republic of China

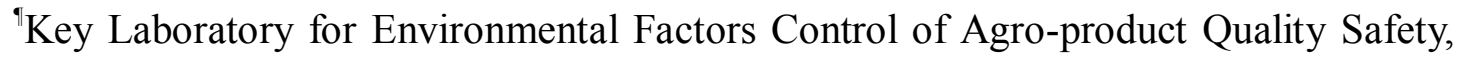
Ministry of Agriculture, Tianjin, 300191, People's Republic of China

${ }^{\S}$ Laboratory of Environmental Factors Risk Assessment of Agro-Product Quality Safety, Ministry of Agriculture, Tianjin, 300191, People's Republic of China 
Table S1. Conditions of gradient elution

\begin{tabular}{cccc}
\hline \multirow{2}{*}{ Time $(\min )$} & \multicolumn{2}{c}{ mobile phase $\varphi(\%)$} & $\begin{array}{c}\text { Flow rate } \\
(\mathrm{mL} / \mathrm{min})\end{array}$ \\
\cline { 2 - 3 } & $\mathrm{A}$ & $\mathrm{B}$ & 0.45 \\
0 & 85 & 15 & 0.45 \\
0.25 & 85 & 15 & 0.45 \\
4 & 25 & 75 & 0.45 \\
6 & 25 & 75 & 0.45 \\
8 & 1 & 99 & 0.45 \\
9 & 1 & 99 & 0.45 \\
\hline
\end{tabular}

Table S2. MRM parameters of the 15 pesticides

\begin{tabular}{|c|c|c|c|c|}
\hline \multirow{2}{*}{ Pesticide } & \multicolumn{2}{|c|}{ Mass-to-charge ratio } & \multirow{2}{*}{$\begin{array}{c}\text { Cone } \\
\text { voltage } \\
(\mathrm{V}) \\
\end{array}$} & \multirow{2}{*}{$\begin{array}{c}\text { Collision } \\
\text { voltage } \\
\text { (V) }\end{array}$} \\
\hline & Parent ion & Daughter ion & & \\
\hline Methomyl & 163.1 & $88.0,105.9^{*}$ & 13 & 9,10 \\
\hline Aldicarb & 191.0 & $88.9,115.9^{*}$ & 10 & 12,5 \\
\hline Carbaryl & 202.1 & $127.1,145.1^{*}$ & 18 & 25,12 \\
\hline Sulfoxide aldicarb & 207.2 & $89.0,132.0 *$ & 18 & 15,7 \\
\hline Carbofuran & 222.2 & $123.1,165.1 *$ & 20 & 20,12 \\
\hline Sulfone aldicarb & 223.2 & $148.0,86.0 *$ & 20 & 10,15 \\
\hline 3-OH carbofuran & 238.0 & $107.0,163.1^{*}$ & 12 & 11,15 \\
\hline Imidacloprid & 256.1 & $175.1,209.1 *$ & 22 & 20,14 \\
\hline Acetamiprid & 223.0 & $56.1,126.0 *$ & 28 & 15,20 \\
\hline Methamidophos & 142.2 & $125.3,93.8^{*}$ & 22 & 13,14 \\
\hline Malathion & 331.0 & $127.1,99.0 *$ & 20 & 14,24 \\
\hline Dimethoate & 247.0 & $125.0,199.0^{*}$ & 6 & 26,14 \\
\hline Diazinon & 305.0 & $153.1,169.0^{*}$ & 34 & 22,26 \\
\hline Phorate & 261.0 & $143.0,74.9^{*}$ & 14 & 8,10 \\
\hline Thiamethoxam & 292.1 & $181.0,211.1^{*}$ & 19 & 25,13 \\
\hline
\end{tabular}

*represents quantified ion

Table S3. Elementary analysis of $\mathrm{Fe}_{3} \mathrm{O}_{4}, \mathrm{Fe}_{3} \mathrm{O}_{4} @ \mathrm{SiO}_{2}-\mathrm{NH}_{2}, \mathrm{MCOFs}$ and COFs

\begin{tabular}{cccc}
\hline $\mathrm{NPs}$ & $\mathrm{C} \%$ & $\mathrm{H} \%$ & $\mathrm{~N} \%$ \\
\hline $\mathrm{Fe}_{3} \mathrm{O}_{4}$ & 1.89 & 0.93 & - \\
$\mathrm{Fe}_{3} \mathrm{O}_{4} @ \mathrm{SiO}_{2}-\mathrm{NH}_{2}$ & 2.69 & 1.70 & 1.92 \\
$\mathrm{MCOFs}$ & 30.10 & 3.17 & 2.39 \\
$\mathrm{COFs}$ & 83.00 & 5.04 & 7.53 \\
\hline
\end{tabular}


Table S4. Isotherm model parameters of MCOFs determined with the Langmuir and Freundlich isotherm models

\begin{tabular}{ccccccccc}
\hline \multirow{2}{*}{ Adsorbent } & \multicolumn{3}{c}{ Langmuir } & & \multicolumn{3}{c}{ Freundlich } \\
\cline { 2 - 4 } \cline { 6 - 8 } & $q_{\max }\left(\mathrm{mg} \mathrm{g}^{-1}\right)$ & $b\left(\mathrm{~L} \mathrm{mg}^{-1}\right)$ & $R^{2}$ & & $K_{\mathrm{F}}$ & $1 / n$ & $R^{2}$ \\
\hline MCOFs & 149.25 & 0.215 & 0.9998 & & 41.313 & 0.362 & 0.9493 \\
\hline
\end{tabular}

Table S5. Kinetic parameters of MCOFs fitted by pseudo-first-order and pseudosecond-order models

\begin{tabular}{lccccc}
\hline \multirow{2}{*}{ Adsorbent } & \multicolumn{2}{c}{ Pseudo-first-order } & & \multicolumn{2}{c}{ Pseudo-second-order } \\
\cline { 2 - 3 } \cline { 5 - 6 } & $k_{1}\left(\mathrm{~min}^{-1}\right)$ & $R^{2}$ & & $k_{2}\left(\mathrm{~g} \mathrm{mg}^{-1} \mathrm{~min}^{-1}\right)$ & $R^{2}$ \\
\hline MCOFs & 0.00325 & 0.2326 & & 0.1154 & 0.9993 \\
\hline
\end{tabular}

Table S6. Recoveries of 15 pesticides after treatment by MCOFs

\begin{tabular}{|c|c|c|c|c|c|c|c|c|c|}
\hline \multirow[b]{2}{*}{ Pesticide } & \multirow{2}{*}{$\begin{array}{l}\text { Added } \\
(\mathrm{ppb})\end{array}$} & \multicolumn{2}{|c|}{ Spinach } & \multicolumn{2}{|c|}{ Kelp } & \multicolumn{2}{|c|}{ Oilseed rape } & \multicolumn{2}{|c|}{ Green pepper } \\
\hline & & $\begin{array}{c}\text { Recovery } \\
(\%)\end{array}$ & $\begin{array}{l}\text { RSD } \\
(\%)\end{array}$ & $\begin{array}{c}\text { Recovery } \\
(\%)\end{array}$ & $\begin{array}{l}\text { RSD } \\
(\%)\end{array}$ & $\begin{array}{c}\text { Recovery } \\
(\%)\end{array}$ & $\begin{array}{c}\text { RSD } \\
(\%)\end{array}$ & $\begin{array}{c}\text { Recovery } \\
(\%)\end{array}$ & $\begin{array}{l}\text { RSD } \\
(\%)\end{array}$ \\
\hline Methomyl & 100.00 & 95.79 & 2.42 & 87.02 & 4.51 & 107.00 & 0.64 & 114.00 & 0.78 \\
\hline Aldicarb & 100.00 & 100.43 & 7.90 & 99.37 & 6.29 & 96.33 & 0.76 & 95.67 & 1.85 \\
\hline Carbaryl & 100.00 & 98.41 & 5.24 & 89.08 & 5.88 & 99.67 & 0.32 & 103.67 & 0.12 \\
\hline $\begin{array}{l}\text { Sulfoxide } \\
\text { aldicarb }\end{array}$ & 100.00 & 96.24 & 6.10 & 92.52 & 3.86 & 101.00 & 0.57 & 99.00 & 0.55 \\
\hline Carbofuran & 100.00 & 104.20 & 7.07 & 100.55 & 7.97 & 110.00 & 0.53 & 105.00 & 0.28 \\
\hline Sulfone aldicarb & 100.00 & 104.13 & 6.31 & 95.27 & 4.04 & 97.00 & 0.30 & 106.33 & 0.99 \\
\hline 3-OH carbofuran & 100.00 & 96.01 & 6.55 & 93.90 & 6.09 & 112.00 & 0.46 & 101.50 & 0.93 \\
\hline Imidacloprid & 100.00 & 96.03 & 6.81 & 105.81 & 1.76 & 112.44 & 4.70 & 100.67 & 0.40 \\
\hline Acetamiprid & 100.00 & 103.27 & 5.12 & 86.72 & 2.24 & 110.00 & 0.44 & 113.00 & 0.58 \\
\hline Methamidophos & 100.00 & 96.69 & 4.29 & 95.77 & 5.09 & 96.33 & 2.01 & 95.74 & 7.36 \\
\hline Malathion & 100.00 & 97.08 & 2.17 & 88.85 & 2.99 & 93.00 & 0.45 & 93.00 & 0.40 \\
\hline Dimethoate & 100.00 & 98.02 & 6.50 & 87.06 & 5.08 & 87.00 & 0.15 & 89.00 & 0.45 \\
\hline Diazinon & 100.00 & 101.75 & 1.48 & 90.76 & 2.74 & 93.00 & 0.35 & 91.67 & 0.15 \\
\hline Phorate & 100.00 & 99.68 & 3.50 & 83.10 & 3.61 & 98.00 & 0.42 & 90.50 & 0.11 \\
\hline Thiamethoxam & 100.00 & 98.42 & 1.01 & 107.33 & 0.93 & 92.00 & 0.52 & 99.67 & 0.70 \\
\hline
\end{tabular}


Table S7. Recoveries of 15 pesticides after treatment by PAN@COF nanofiber films

\begin{tabular}{|c|c|c|c|c|c|c|c|c|c|c|c|c|c|c|c|c|c|}
\hline \multirow{3}{*}{ Pesticide } & \multirow{3}{*}{$\begin{array}{l}\text { Add } \\
(\mathrm{ppb})\end{array}$} & \multicolumn{4}{|c|}{$30 \mathrm{mg}$} & \multicolumn{4}{|c|}{$50 \mathrm{mg}$} & \multicolumn{4}{|c|}{$70 \mathrm{mg}$} & \multicolumn{4}{|c|}{$90 \mathrm{mg}$} \\
\hline & & \multicolumn{2}{|c|}{ immersion } & \multicolumn{2}{|c|}{ filtration } & \multicolumn{2}{|c|}{ immersion } & \multicolumn{2}{|c|}{ filtration } & \multicolumn{2}{|c|}{ immersion } & \multicolumn{2}{|c|}{ filtration } & \multicolumn{2}{|c|}{ immersion } & \multicolumn{2}{|c|}{ filtration } \\
\hline & & $\begin{array}{c}\text { Recovery } \\
(\%)\end{array}$ & $\begin{array}{c}\text { RSD } \\
(\%)\end{array}$ & $\begin{array}{c}\text { Recovery } \\
(\%)\end{array}$ & $\begin{array}{l}\text { RSD } \\
(\%)\end{array}$ & $\begin{array}{c}\text { Recovery } \\
(\%)\end{array}$ & $\begin{array}{c}\text { RSD } \\
(\%)\end{array}$ & $\begin{array}{c}\text { Recovery } \\
(\%)\end{array}$ & $\begin{array}{c}\text { RSD } \\
(\%)\end{array}$ & $\begin{array}{c}\text { Recovery } \\
(\%)\end{array}$ & $\begin{array}{l}\text { RSD } \\
(\%)\end{array}$ & $\begin{array}{c}\text { Recovery } \\
(\%)\end{array}$ & $\begin{array}{l}\text { RSD } \\
(\%)\end{array}$ & $\begin{array}{c}\text { Recovery } \\
(\%)\end{array}$ & $\begin{array}{c}\text { RSD } \\
(\%)\end{array}$ & $\begin{array}{c}\text { Recovery } \\
(\%)\end{array}$ & $\begin{array}{c}\text { RSD } \\
(\%)\end{array}$ \\
\hline Methomyl & 100.00 & 96.22 & 0.40 & 59.91 & 0.49 & 83.92 & 0.01 & 27.90 & 18.20 & 89.23 & 2.15 & 21.40 & 3.59 & 55.85 & 19.87 & 4.42 & 4.59 \\
\hline Aldicarb & 100.00 & 101.96 & 5.13 & 49.40 & 5.95 & 74.54 & 4.75 & 20.73 & 13.93 & 75.59 & 1.90 & 12.64 & 5.52 & 47.89 & 2.01 & 3.40 & 4.78 \\
\hline Carbaryl & 100.00 & 97.43 & 10.52 & 35.33 & 1.99 & 66.65 & 8.82 & 11.10 & 0.75 & 61.82 & 0.68 & 3.45 & 1.04 & 68.39 & 4.39 & 2.17 & 6.43 \\
\hline $\begin{array}{l}\text { Sulfoxide } \\
\text { aldicarb }\end{array}$ & 100.00 & 94.64 & 9.67 & 58.42 & 5.20 & 89.60 & 2.58 & 29.20 & 8.34 & 93.51 & 4.82 & 22.04 & 2.73 & 95.45 & 5.13 & 4.31 & 8.30 \\
\hline Carbofuran & 100.00 & 107.35 & 5.13 & 46.82 & 5.95 & 88.10 & 0.68 & 22.45 & 10.19 & 79.37 & 5.91 & 8.30 & 0.68 & 78.23 & 3.86 & 3.92 & 15.50 \\
\hline Sulfone aldicarb & 100.00 & 100.77 & 6.58 & 108.67 & 5.59 & 66.64 & 3.60 & 58.23 & 2.11 & 82.38 & 4.47 & 42.21 & 6.46 & 39.22 & 11.51 & 16.82 & 15.38 \\
\hline 3-OH carbofuran & 100.00 & 104.20 & 1.55 & 73.18 & 6.55 & 56.43 & 1.95 & 37.92 & 1.61 & 28.89 & 7.18 & 20.69 & 9.20 & 44.45 & 0.65 & 11.13 & 13.34 \\
\hline Imidacloprid & 100.00 & 73.24 & 4.18 & 66.23 & 4.96 & 45.93 & 1.70 & 40.69 & 3.57 & 31.41 & 0.68 & 29.01 & 2.00 & 26.07 & 7.99 & 3.41 & 2.59 \\
\hline Acetamiprid & 100.00 & 97.37 & 0.68 & 90.60 & 4.79 & 50.79 & 4.84 & 49.82 & 15.24 & 43.84 & 2.72 & 21.20 & 2.97 & 37.47 & 3.49 & 9.80 & 2.30 \\
\hline Methamidophos & 100.00 & 81.53 & 1.13 & 99.95 & 2.98 & 84.43 & 2.37 & 35.89 & 5.82 & 50.02 & 9.34 & 27.80 & 5.72 & 49.99 & 3.72 & 17.92 & 4.86 \\
\hline Malathion & 100.00 & 77.52 & 1.27 & 71.60 & 4.30 & 60.97 & 7.73 & 40.04 & 3.05 & 57.01 & 1.46 & 38.96 & 7.02 & 51.96 & 6.03 & 6.43 & 10.56 \\
\hline Dimethoate & 100.00 & 60.52 & 2.75 & 56.70 & 2.70 & 41.69 & 8.70 & 20.75 & 11.13 & 22.04 & 2.52 & 19.42 & 3.89 & 23.07 & 2.40 & 12.45 & 2.57 \\
\hline Diazinon & 100.00 & 86.39 & 1.42 & 78.62 & 5.49 & 63.66 & 5.48 & 50.03 & 2.83 & 63.64 & 8.46 & 42.37 & 3.32 & 51.69 & 2.71 & 9.66 & 9.25 \\
\hline Phorate & 100.00 & 94.28 & 1.03 & 93.63 & 3.98 & 99.48 & 5.40 & 91.85 & 4.98 & 101.27 & 1.60 & 79.71 & 5.73 & 94.47 & 0.14 & 10.82 & 1.11 \\
\hline Thiamethoxam & 100.00 & 97.93 & 0.56 & 85.85 & 0.63 & 95.30 & 9.88 & 85.83 & 4.03 & 77.78 & 1.71 & 61.70 & 4.93 & 67.97 & 0.02 & 52.61 & 4.19 \\
\hline
\end{tabular}


Table S8. Isotherm model parameters of PAN@COF film determined with the Langmuir and Freundlich isotherm models

\begin{tabular}{ccccccccc}
\hline \multirow{2}{*}{ Adsorbent } & \multicolumn{3}{c}{ Langmuir } & & \multicolumn{3}{c}{ Freundlich } \\
\cline { 2 - 4 } \cline { 6 - 8 } & $q_{\max }\left(\mathrm{mg} \mathrm{g}^{-1}\right)$ & $b\left(\mathrm{~L} \mathrm{mg}^{-1}\right)$ & $R^{2}$ & & $K_{\mathrm{F}}$ & $1 / n$ & $R^{2}$ \\
\hline PAN@COF & 1.054 & 0.075 & 0.9939 & & 0.111 & 0.594 & 0.9927 \\
\hline
\end{tabular}

Table S9. Kinetic parameters of PAN@COF film fitted by pseudo-first-order and pseudo-second-order models

\begin{tabular}{llllcc}
\hline \multirow{2}{*}{ Adsorbent } & \multicolumn{2}{c}{ Pseudo-first-order } & & \multicolumn{2}{c}{ Pseudo-second-order } \\
\cline { 2 - 3 } \cline { 5 - 6 } & $k_{1}\left(\mathrm{~min}^{-1}\right)$ & $R^{2}$ & & $k_{2}\left(\mathrm{~g} \mathrm{mg}^{-1} \mathrm{~min}^{-1}\right)$ & $R^{2}$ \\
\hline PAN@COF & $4.570 \times 10^{-4}$ & 0.3390 & & 36.36 & 0.9997 \\
\hline
\end{tabular}


Table S10. Comparison of the proposed method with other reported methods

\begin{tabular}{|c|c|c|c|c|c|c|c|}
\hline Method & Sorbent & Amount of sorbent (mg) & $\begin{array}{l}\text { Adsorption } \\
\text { time (min) }\end{array}$ & $\begin{array}{l}\text { Recycle } \\
\text { times }\end{array}$ & $\begin{array}{c}\text { Recovery } \\
(\%) \\
\end{array}$ & $\begin{array}{l}\mathrm{RSD} \\
(\%)\end{array}$ & Ref. \\
\hline QuEChERS & $\begin{array}{c}\mathrm{NaOAc} \mathrm{MgSO}_{4}, \\
\text { PSA, } \mathrm{C}_{18}, \\
\text { CarbonX Plus }\end{array}$ & $\begin{array}{c}\text { Kit } \mathrm{A}\left(6.0 \mathrm{~g} \mathrm{MgSO}_{4} \text { and } 1.5 \mathrm{~g} \mathrm{NaOAc}\right) \\
\text { and Kit B (Solid-phase extraction } 150 \\
\mathrm{mg} \mathrm{MgSO}_{4}, 50 \mathrm{mg} \text { PSA, } 50 \mathrm{mg} \mathrm{C}_{18} \text { y, } 50 \\
\text { mg CarbonX Plus) }\end{array}$ & 29.25 & - & $84.4-119.6$ & $\begin{array}{c}<7.2 \\
\text { (intraday) } \\
<1.1 \\
\text { (interday) }\end{array}$ & 1 \\
\hline Modified QuEChERS & $\begin{array}{l}\mathrm{C}_{18}, \mathrm{PSA} \text { and } \mathrm{Z}- \\
\mathrm{Sep}+(\text { hybrid } \\
\text { material made up } \\
\text { of zirconia and } \\
\left.\quad \mathrm{C}_{18}\right)\end{array}$ & $\begin{array}{l}\text { Combination 1: } 25 \mathrm{mg} \mathrm{C}_{18}+25 \mathrm{mg} \text { PSA } \\
\text { Combination 2: } 20 \mathrm{mg} \mathrm{C}_{18}+20 \mathrm{mg} \text { PSA } \\
+10 \mathrm{mg} \mathrm{Z-Sep}+ \\
\text { Combination 3: } 25 \mathrm{mg} \mathrm{C}_{18}+15 \mathrm{mg} \text { PSA } \\
\quad+10 \mathrm{mg} \mathrm{Z-Sep}+\end{array}$ & 56 & - & $63-129$ & $\leq 21.5$ & 2 \\
\hline $\begin{array}{c}\text { QuEChERS + } \\
\text { Dispersive solid phase } \\
\text { extraction }\end{array}$ & $\begin{array}{l}\text { amino-modified } \\
\text { multi-walled } \\
\text { carbon nanotubes } \\
\left(\mathrm{MWCNTs}_{\mathrm{N} H}\right) \\
\text { and } \mathrm{C}_{18}\end{array}$ & $\begin{array}{c}10 \mathrm{mg} \text { of MWCNTs- } \mathrm{NH}_{2}, 10 \mathrm{mg} \text { of } \mathrm{C}_{18} \\
\text { and } 150 \mathrm{mg} \text { of anhydrous } \mathrm{MgSO}_{4}\end{array}$ & 9 & - & 81.8-102 & $9.5-15.3$ & 3 \\
\hline $\begin{array}{l}\text { Magnetic solid phase } \\
\text { extraction }\end{array}$ & $\begin{array}{c}\mathrm{Fe}_{3} \mathrm{O}_{4} @ \mathrm{SiO}_{2} @ \mathrm{KI} \\
\mathrm{T}-6\end{array}$ & $0.4 \mathrm{mg} / \mathrm{mL}$ & 10 & 10 & $86.58-98.80$ & $0.13-4.71$ & 4 \\
\hline Solid phase extraction & $\mathrm{NH}_{2} @ \mathrm{COF}$ & $10 \mathrm{mg} / \mathrm{mL}$ & - & 50 & 89.6-102.4 & $\leq 7.1$ & 5 \\
\hline Solid phase extraction & $\begin{array}{l}\text { imine-linked } \\
\text { molecularly }\end{array}$ & $0.1 \mathrm{mg} / \mathrm{mL}$ & 40 & 50 & $94.3-102.7$ & $3.2-7.3$ & 6 \\
\hline
\end{tabular}




\begin{tabular}{|c|c|c|c|c|c|c|c|}
\hline & $\begin{array}{c}\text { imprinted covalent } \\
\text { organic } \\
\text { frameworks } \\
\text { (MICOFs) }\end{array}$ & & & & & & \\
\hline $\begin{array}{l}\text { Fabric phase sorptive } \\
\text { extraction }\end{array}$ & $\begin{array}{l}\text { PTFE covered } \\
\text { magnetic stir bar }\end{array}$ & $3.3 \mathrm{mg}$ & $6-15 \mathrm{~h}$ & 5 & $77-121$ & $4-6$ & 7 \\
\hline Liquid-liquid extraction & DESs & 1:2 molar ratio & 4.2 & 4 & $\begin{array}{c}99.2 \text { (basic), } \\
98.2 \text { (non } \\
\text { basic) }\end{array}$ & - & 8 \\
\hline $\begin{array}{l}\text { Magnetic solid phase } \\
\text { microextraction }\end{array}$ & $\begin{array}{c}\mathrm{Fe}_{3} \mathrm{O}_{4} @ \mathrm{SiO}_{2-} \\
\mathrm{NH}_{2} @ \mathrm{COFs}\end{array}$ & $1-3 \mathrm{mg} / \mathrm{mL}$ & 5 & 10 & $83.10-114.00$ & $0.11-7.97$ & This work \\
\hline Solid phase extraction & $\begin{array}{c}\text { electrospun } \\
\text { COFs/polyacrylon } \\
\text { itrile nanofibers }\end{array}$ & $30 \mathrm{mg}$ & 10 & 10 & $60.52-107.35$ & $0.40-10.52$ & This work \\
\hline
\end{tabular}




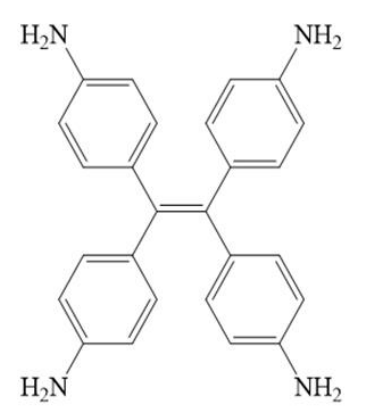

ETTA

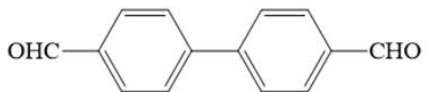

BPDA

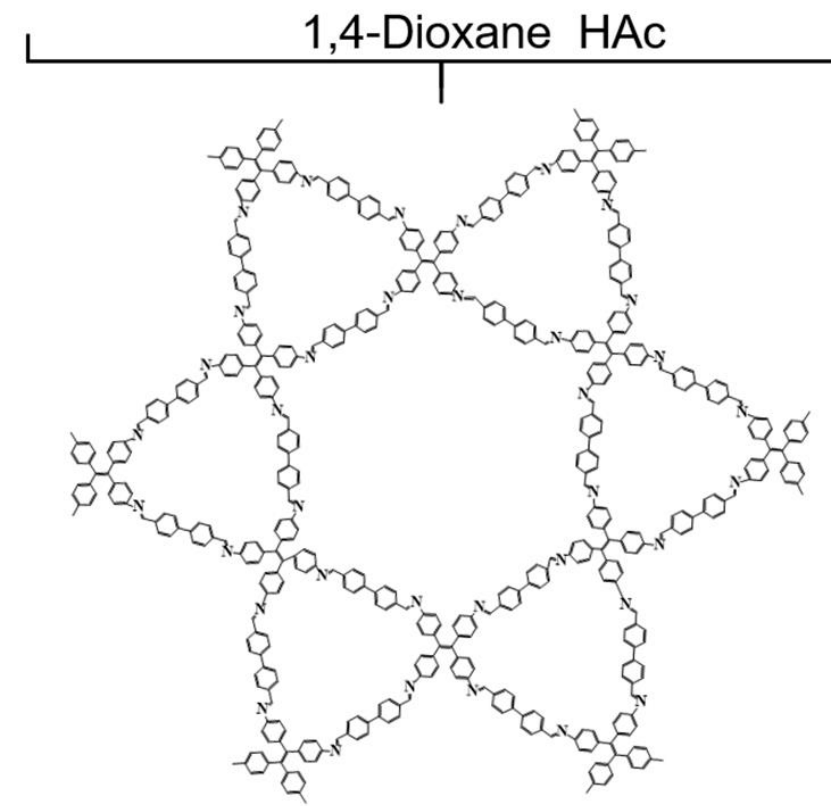

\section{Heteropore COFs}

Scheme S1. Preparation of heteropore COFs using ETTA and BPDA as monomers 

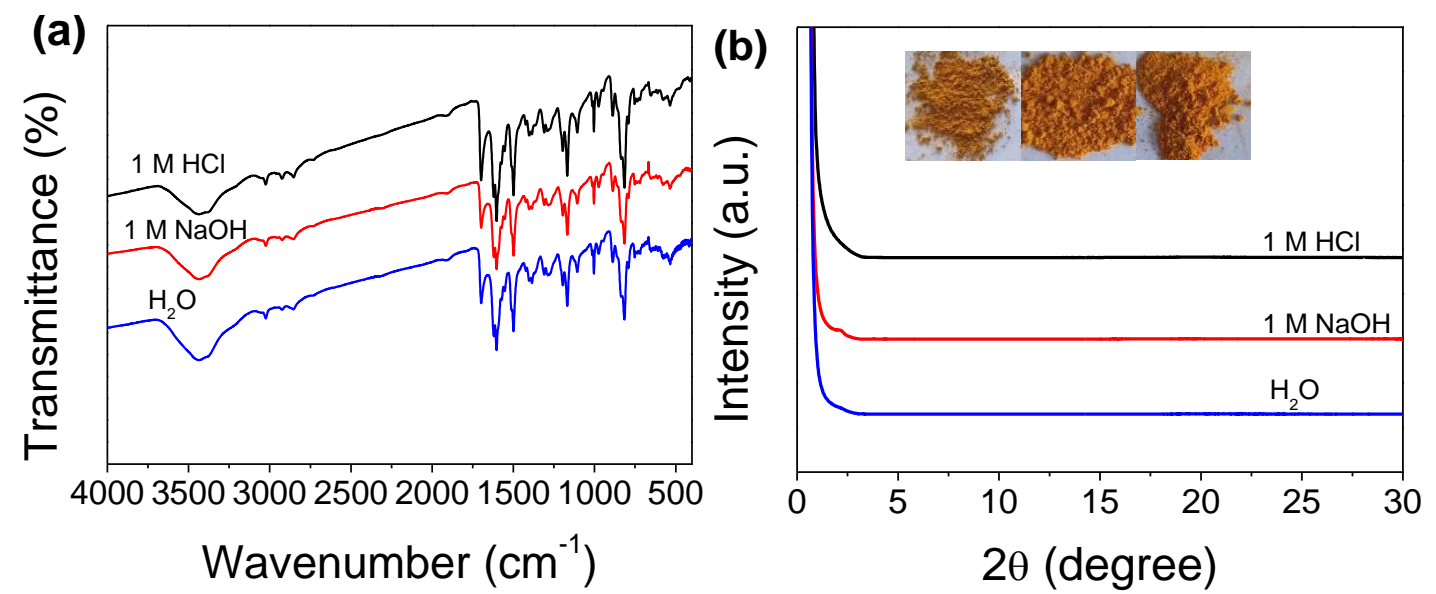

Fig. S1. (a) FT-IR spectra and (b) XRD diffractograms of heteropore COFs treated with $1 \mathrm{M} \mathrm{HCl}$, $1 \mathrm{M} \mathrm{NaOH}$ and $\mathrm{H}_{2} \mathrm{O}$ for 3 days.
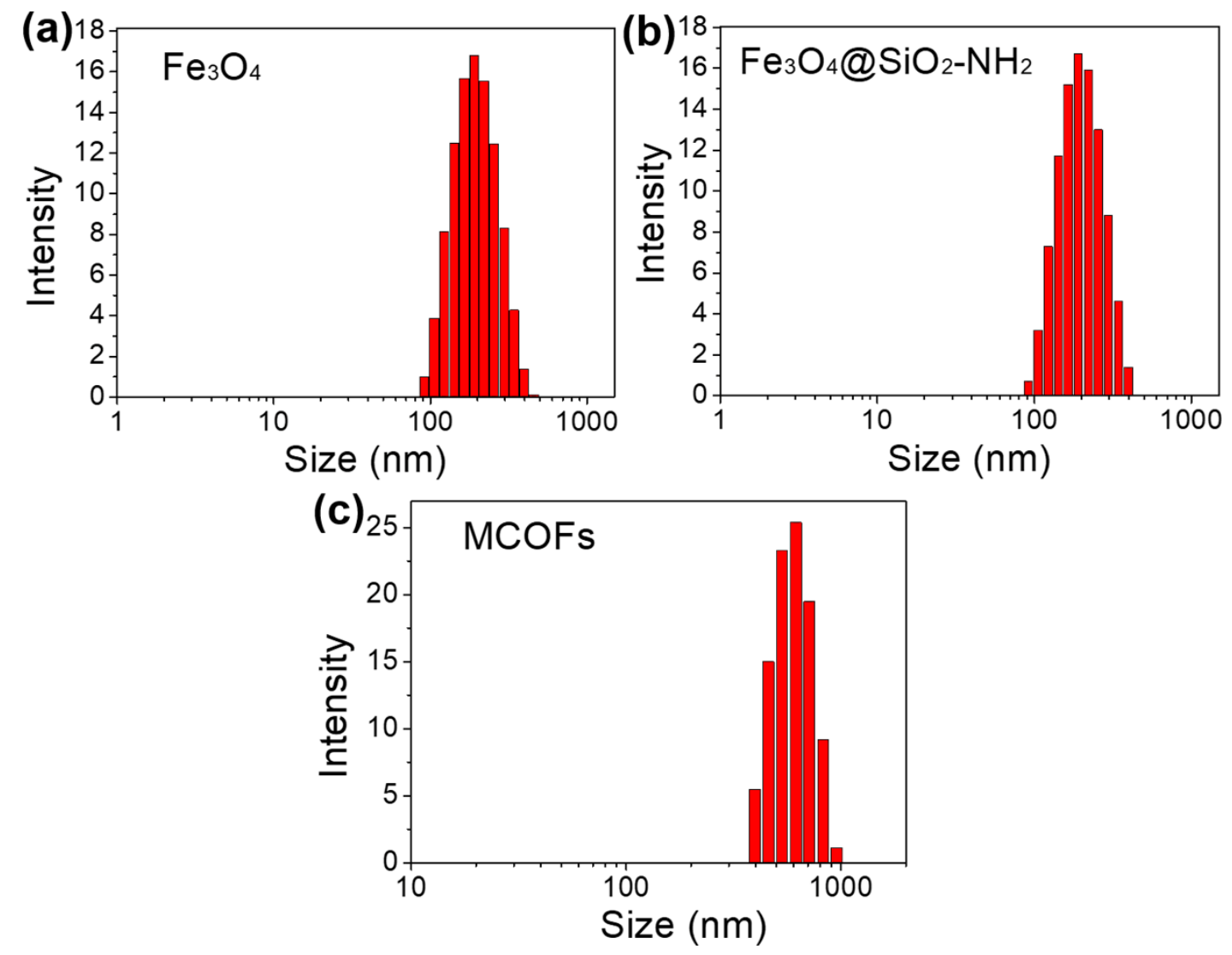

Fig. S2. Size distribution of (a) $\mathrm{Fe}_{3} \mathrm{O}_{4}$, (b) $\mathrm{Fe}_{3} \mathrm{O}_{4} @ \mathrm{SiO}_{2}-\mathrm{NH}_{2}$ and (c) MCOFs in water tested by DLS. 


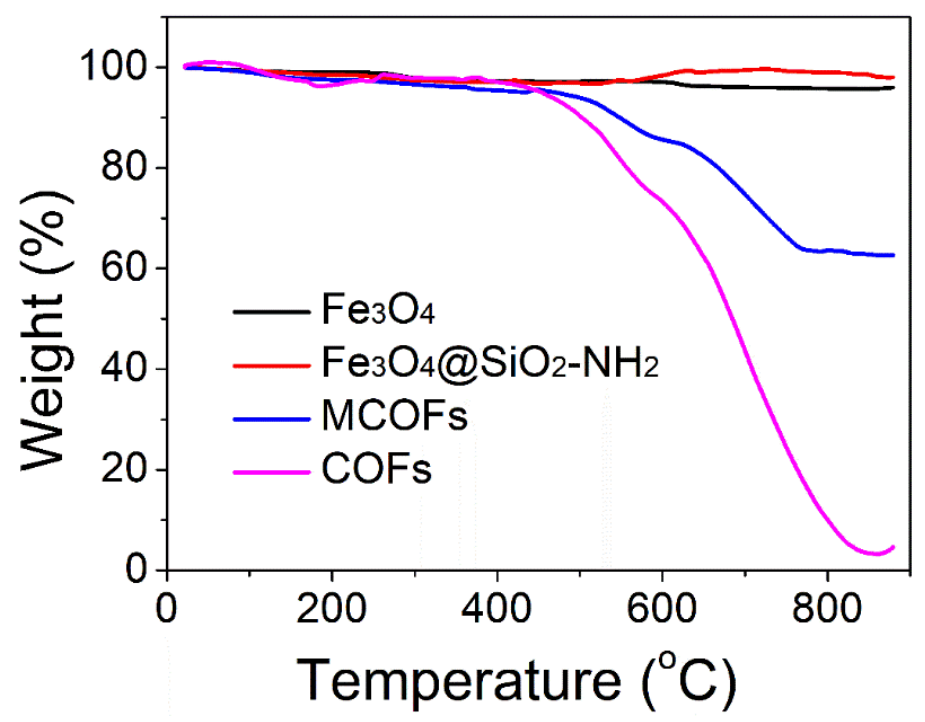

Fig. S3. TG curves of $\mathrm{Fe}_{3} \mathrm{O}_{4}, \mathrm{Fe}_{3} \mathrm{O}_{4} @ \mathrm{SiO}_{2}-\mathrm{NH}_{2}, \mathrm{MCOFs}$ and COFs.

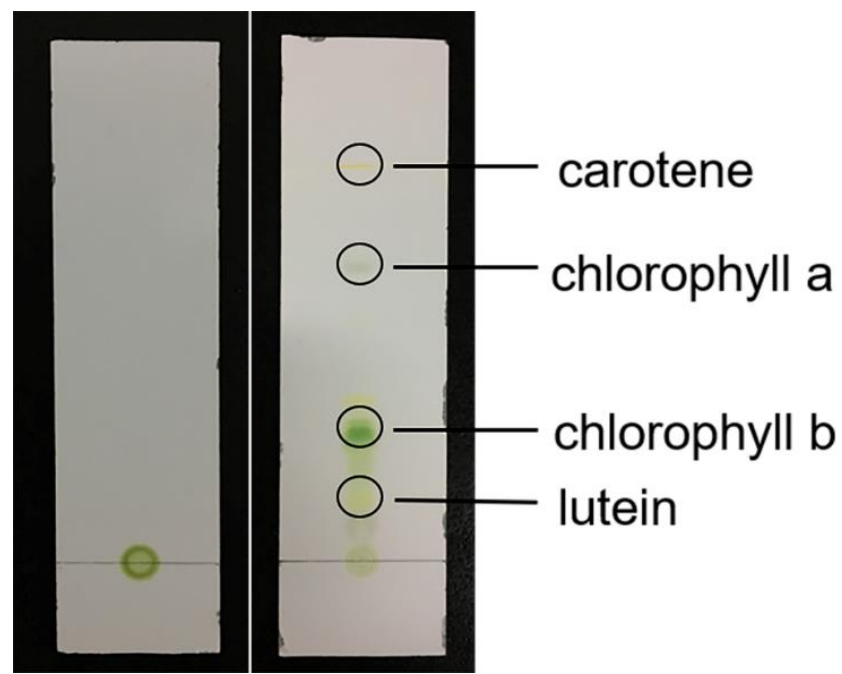

Fig. S4. Separation of spinach extracts by thin layer chromatography. 


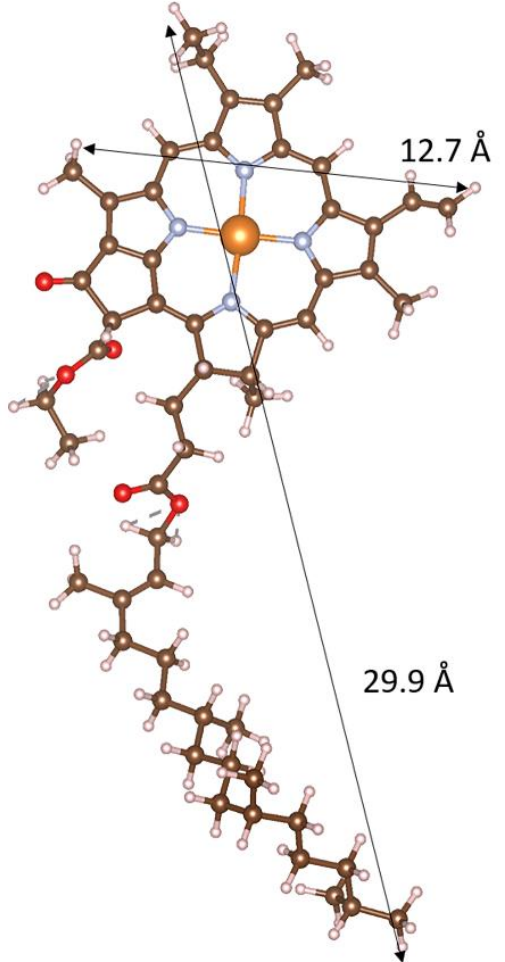

Chlorophyll a

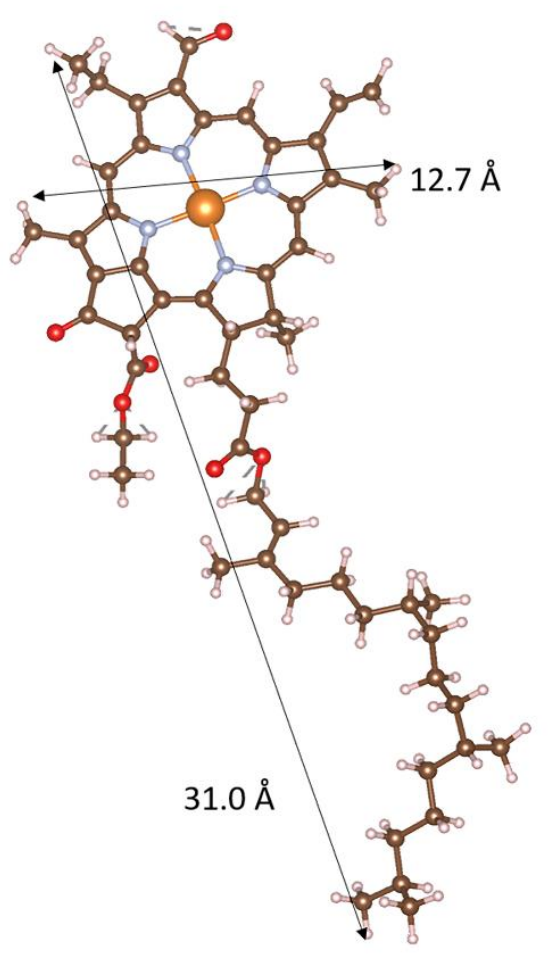

Chlorophyll b

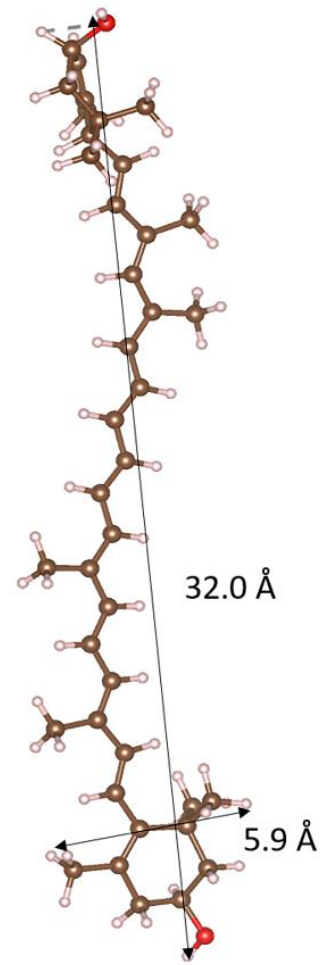

Lutein

Fig. S5. The calculated sizes of chlorophyll a, chlorophyll b and lutein using ORCA program?
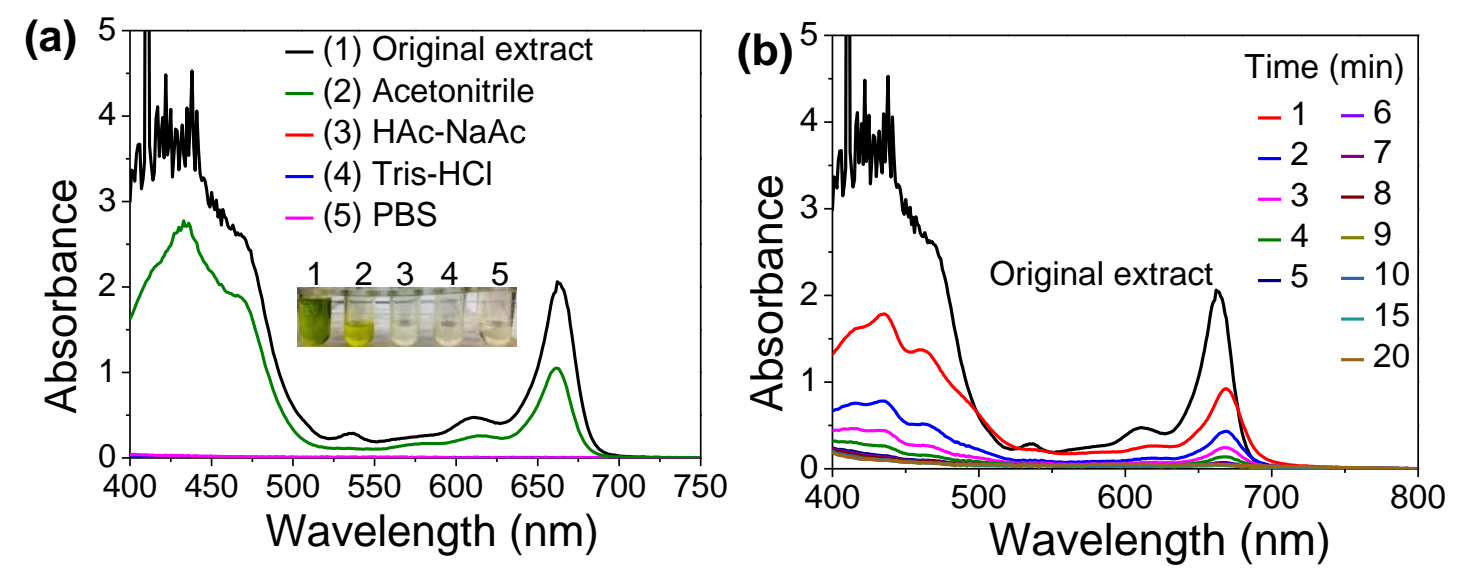

Fig. S6. (a) UV-vis absorption spectra of phytochromes before and after addition of $3 \mathrm{mg} / \mathrm{mL}$ MCOFs in different buffers ( $\mathrm{pH}$ 6.0). The insert shows the solution photos after treatment with MCOFs. (b) Time-dependent UV-vis absorption spectra of phytochromes after addition of $1 \mathrm{mg} / \mathrm{mL}$ MCOFs. These two figures are the complete spectra of Fig. 2a and Fig. 2c, respectively. 

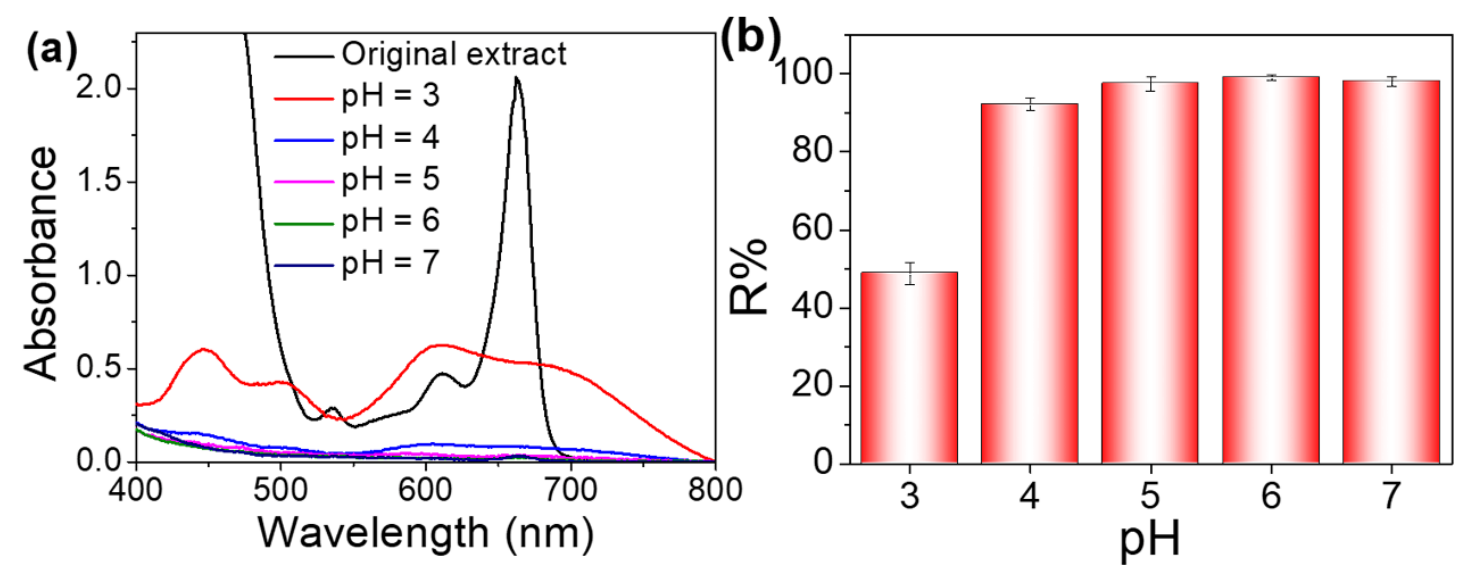

Fig. S7. pH-dependent removal of phytochromes. (a) UV-vis absorption spectra of phytochromes before and after addition of $1 \mathrm{mg} / \mathrm{mL}$ MCOFs in HAc-NaAc buffer with different $\mathrm{pH}$ values. (b) The removal percentage of phytochromes under different $\mathrm{pH}$ conditions.
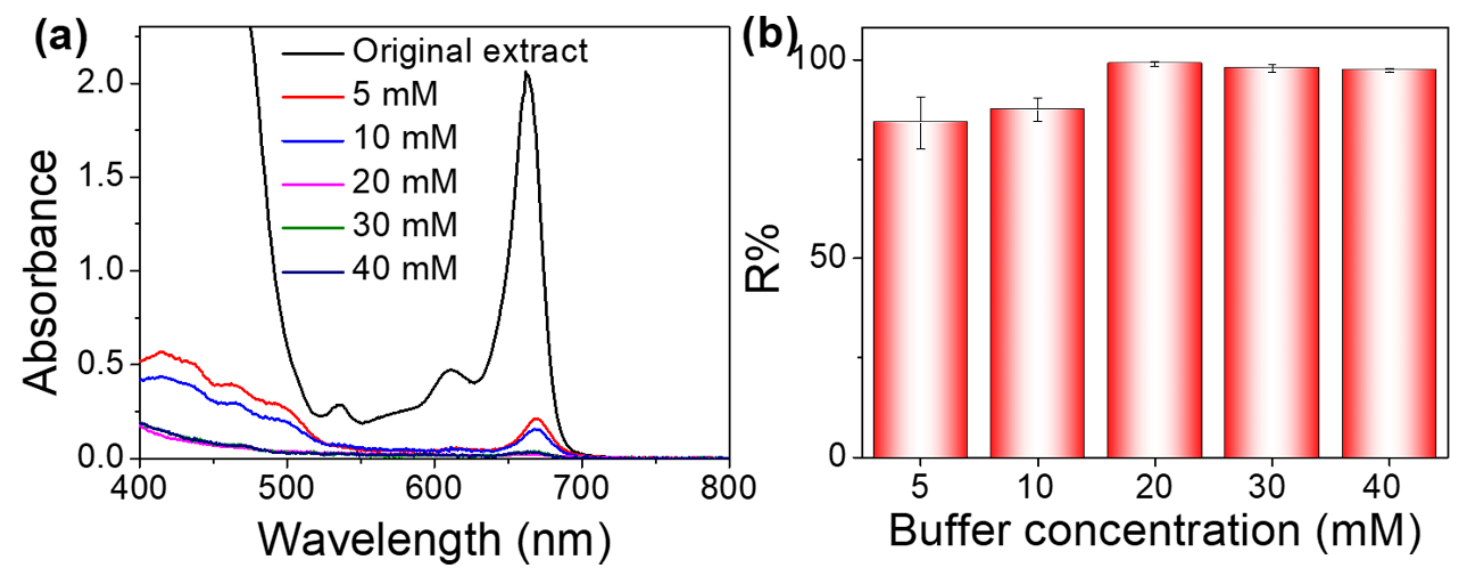

Fig. S8. HAc-NaAc buffer concentration-dependent removal of phytochromes. (a) UV-vis absorption spectra of phytochromes before and after addition of $1 \mathrm{mg} / \mathrm{mL}$ MCOFs in different concentrations of HAc-NaAc buffer ( $\mathrm{pH}$ 6.0). (b) The removal percentage of phytochromes under different buffer concentration conditions. 

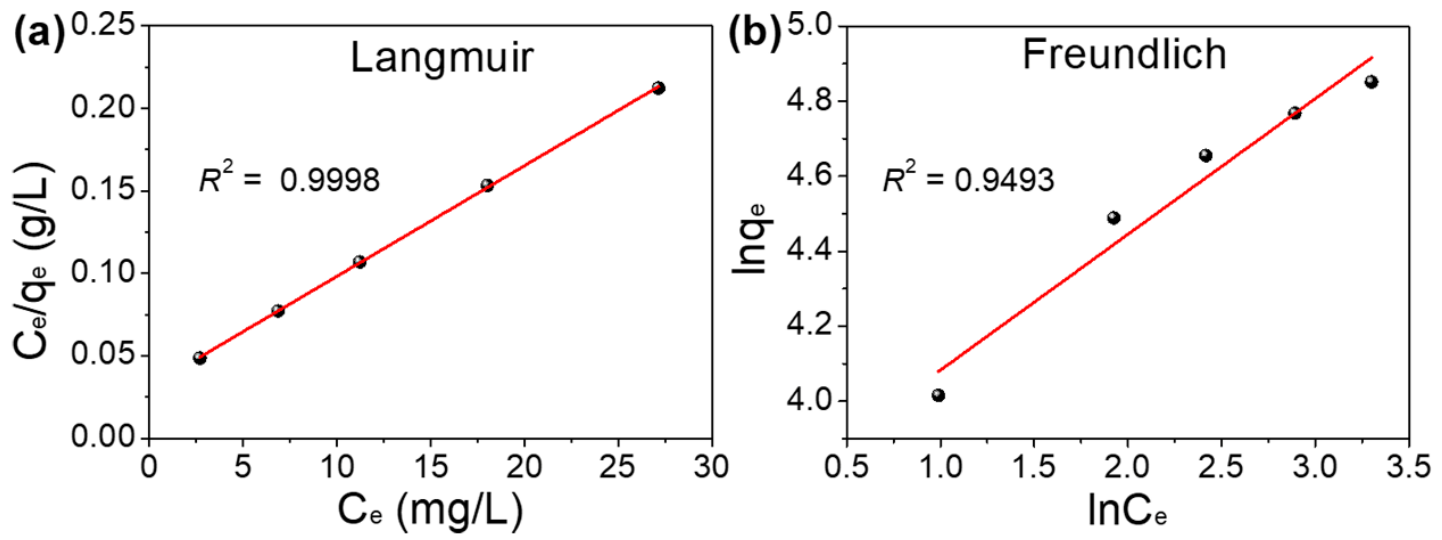

Fig. S9. Static equilibrium absorption isotherms of MCOFs fitted by (a) Langmuir and (b) Freundlich models.
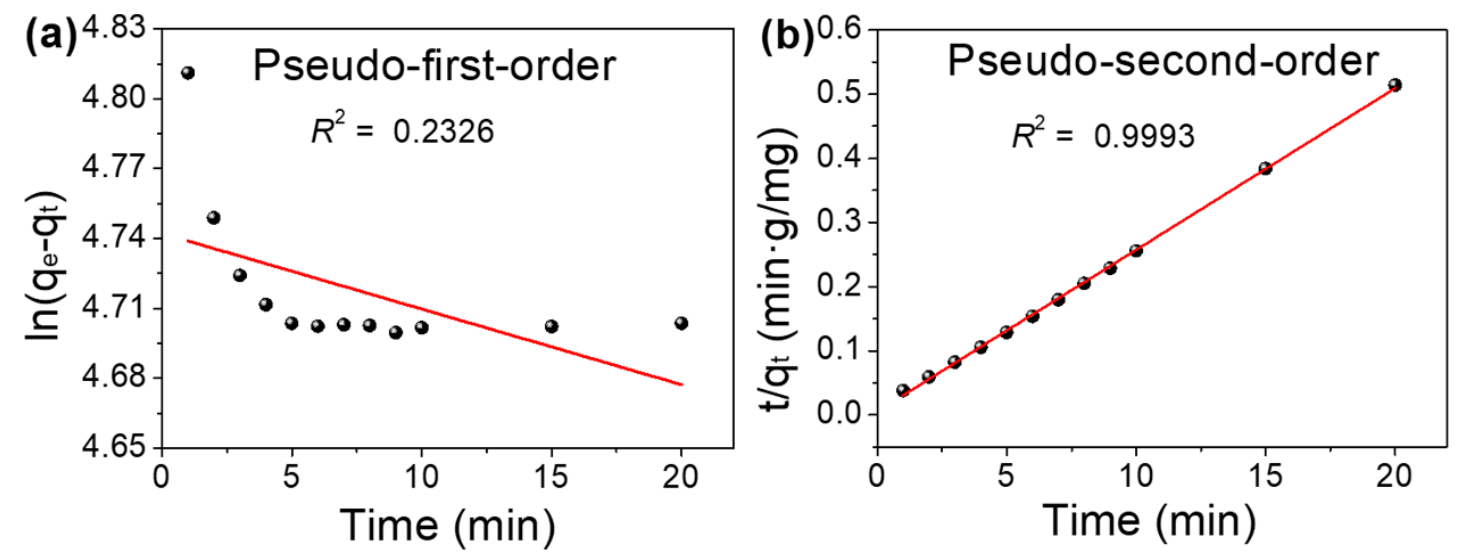

Fig. S10. Phytochrome adsorption kinetics characterization of MCOFs by (a) pseudo-first-order and (b) pseudo-second-order kinetic models.

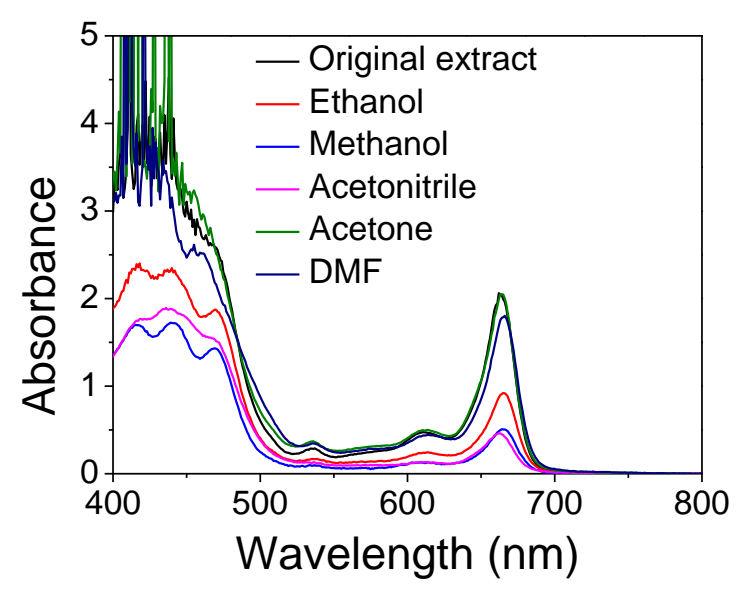

Fig. S11. UV-vis spectra of different eluents. This figure is the complete spectrum of Fig. 3a. 

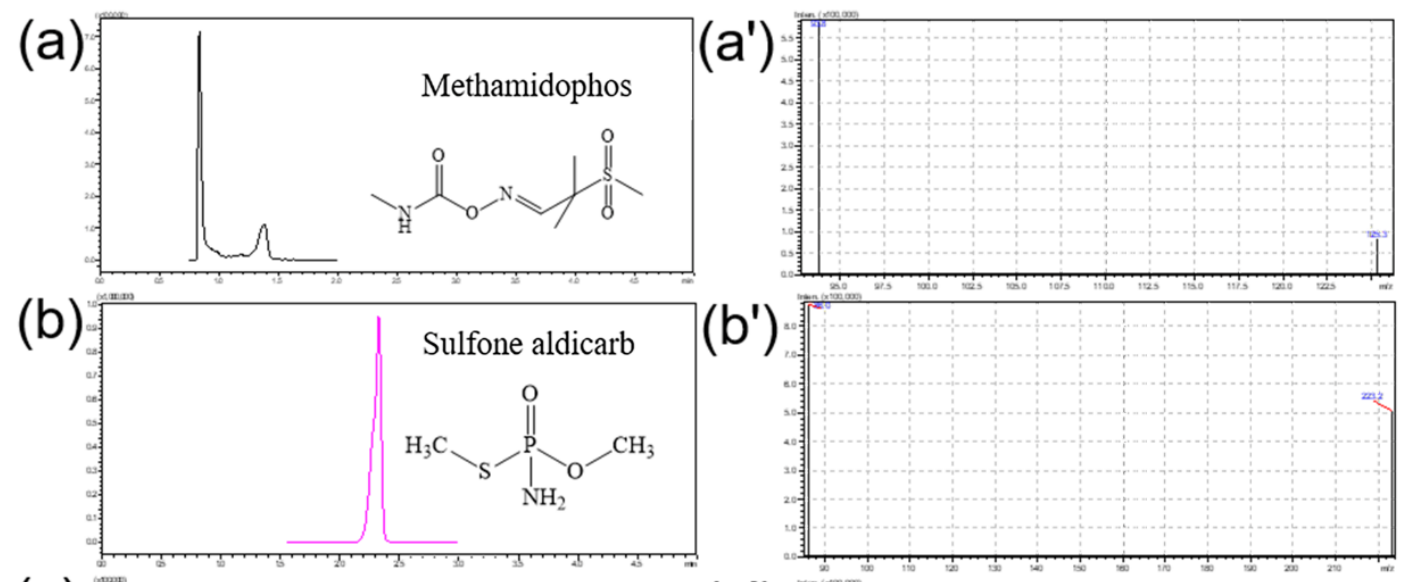

(c)

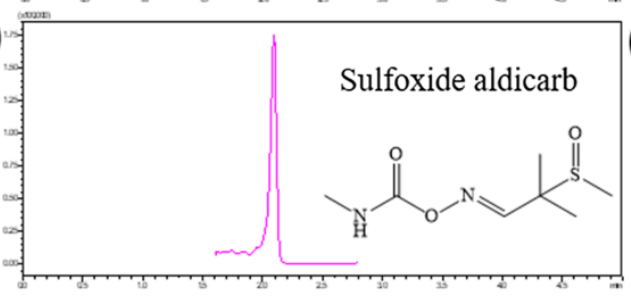

(d)

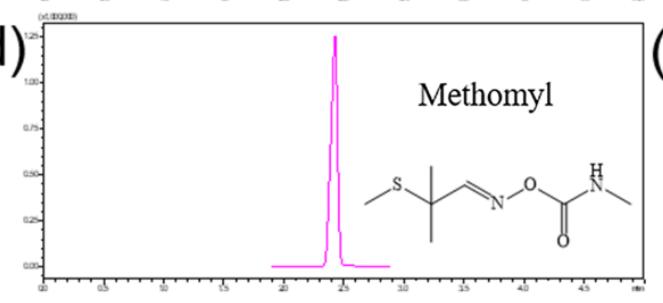

(e)

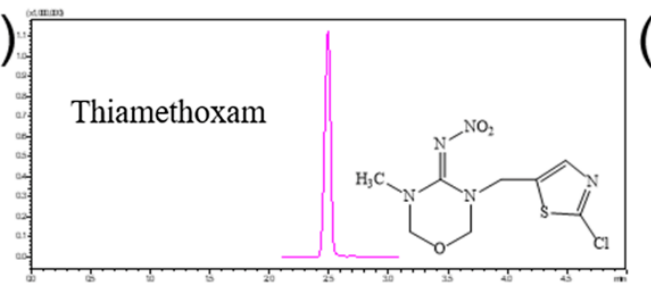

(f)

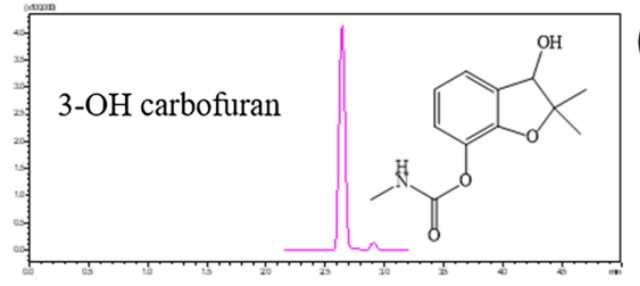

(g)

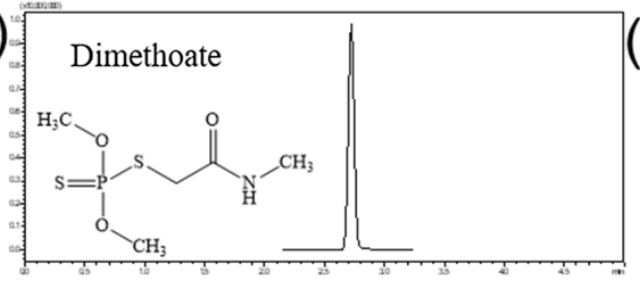

(h)

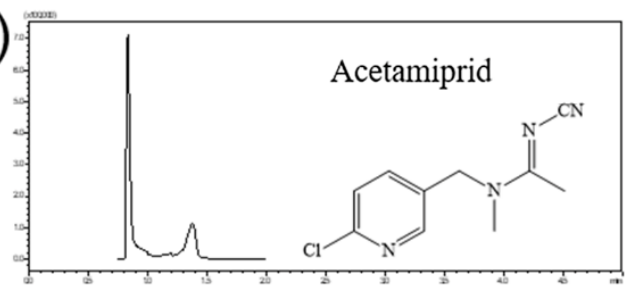

(c')

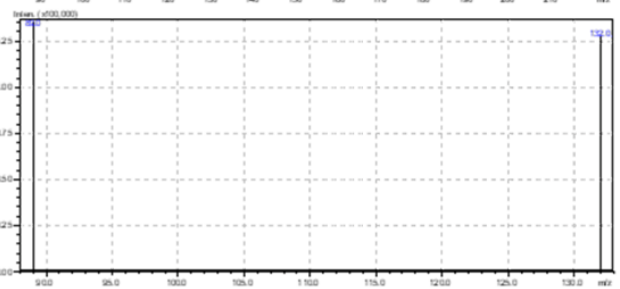

(d')

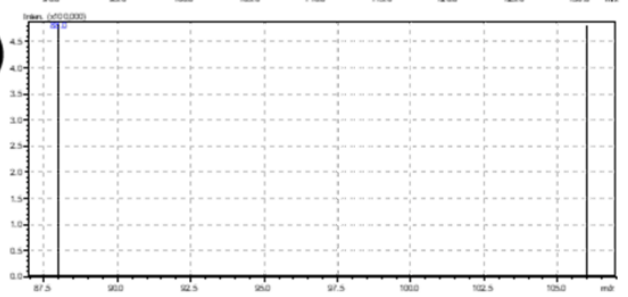

(e')

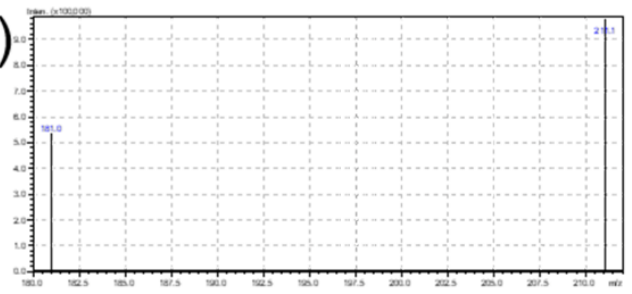

(f')

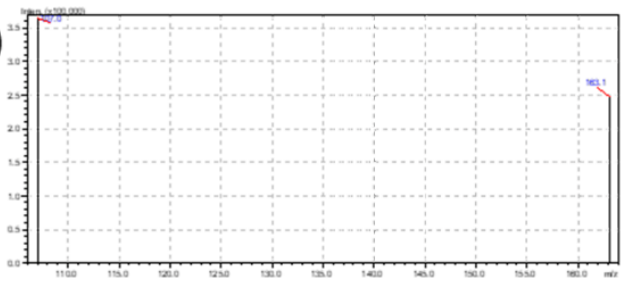

(g')

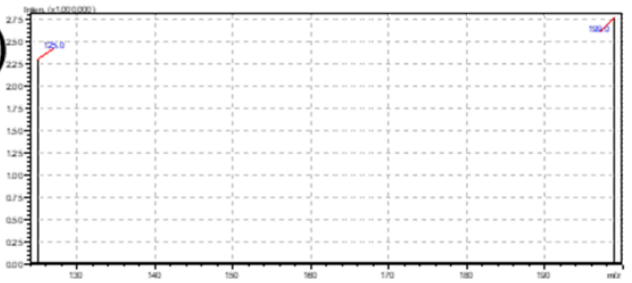

(h')

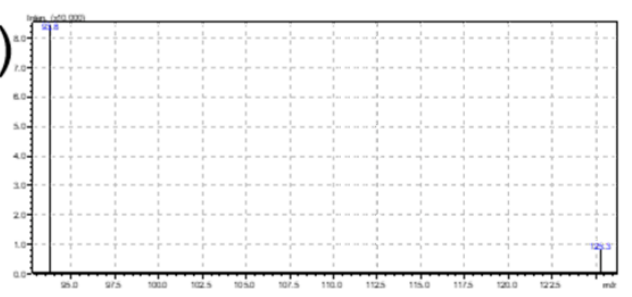


(i)
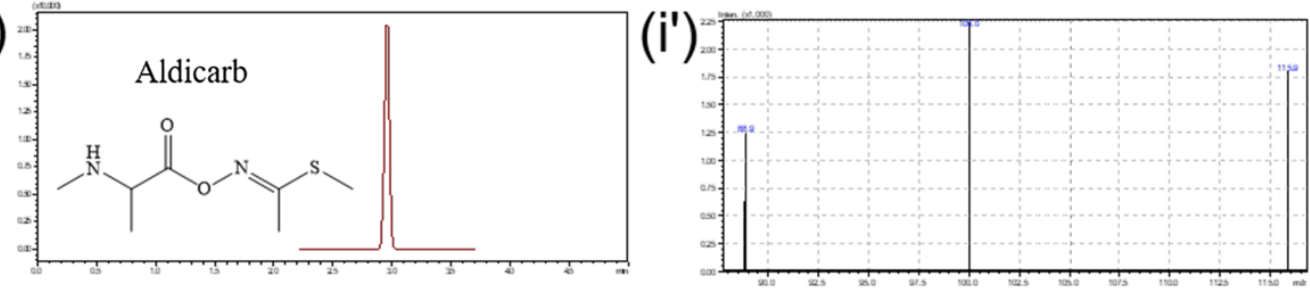

(j)
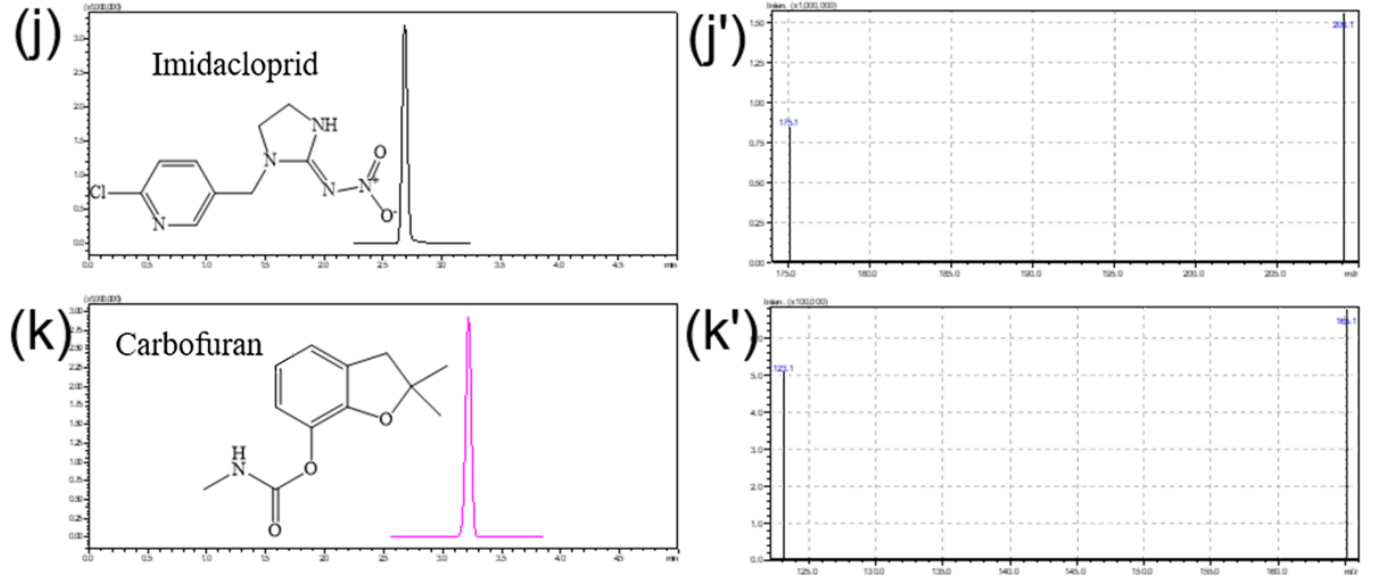

(I)
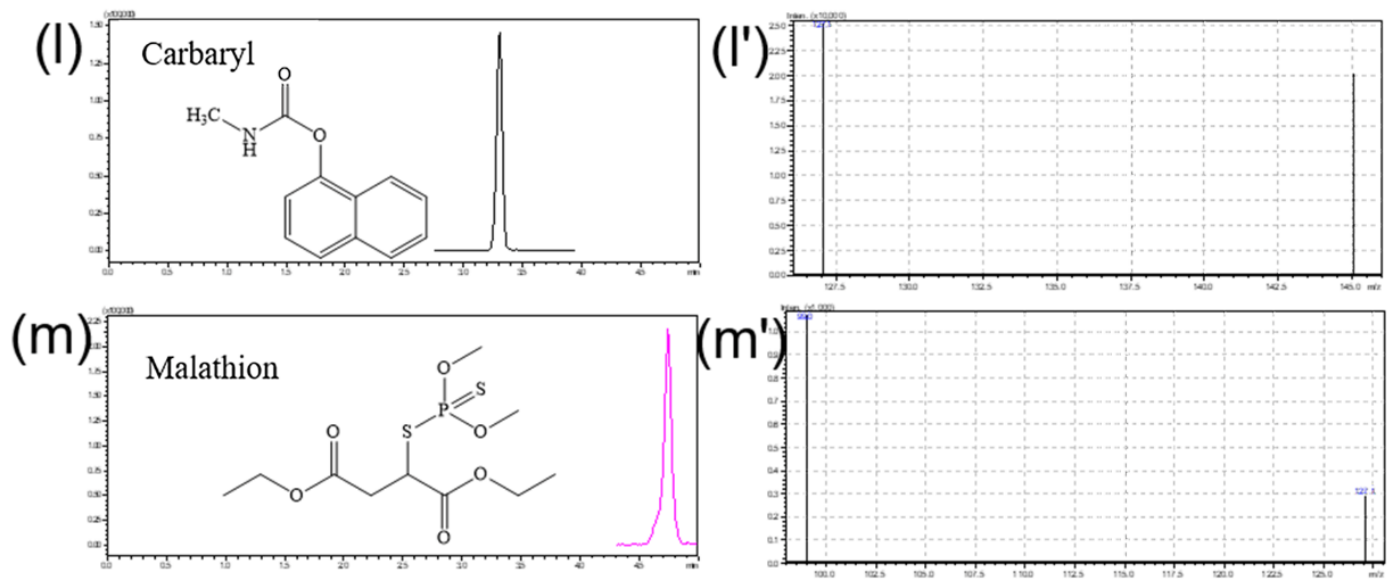

(n)
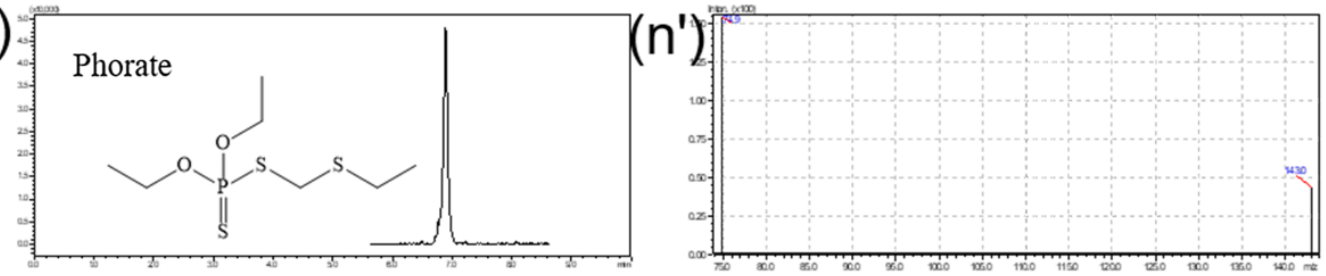

(o)
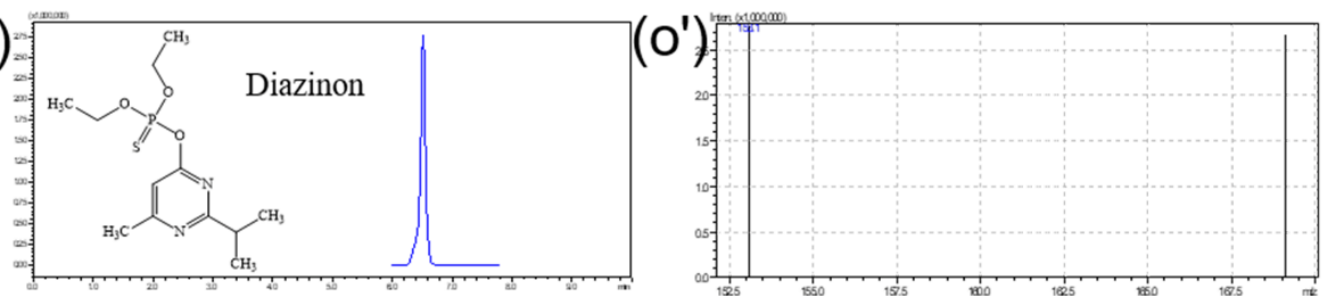

Fig. S12. Chromatograms (Left) and mass spectra (Right) of 15 pesticides. 

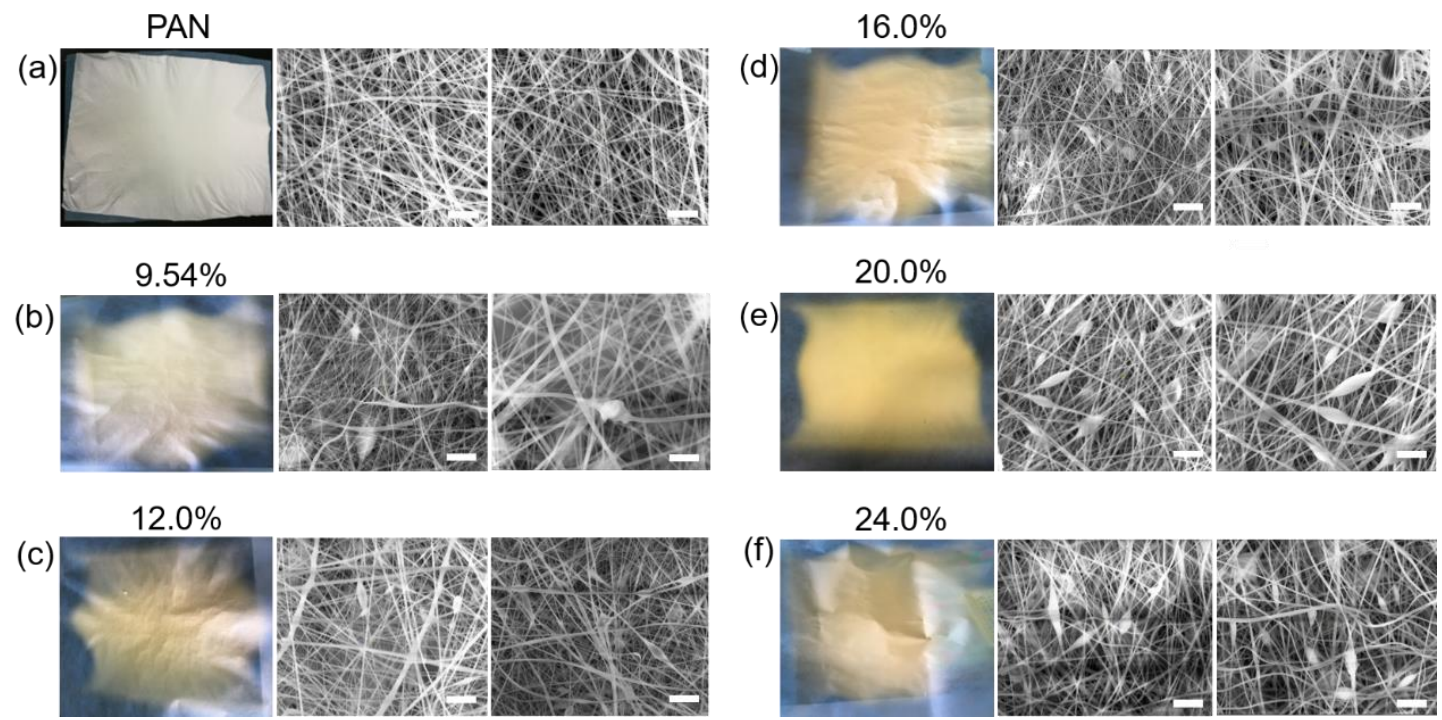

Fig. S13. Photographs and SEM images of the electrospun PAN@COF nanofiber films with COFsload ratio of (a) 0 , (b) 9.54, (c) 12.0, (d) 16.0, (e) 20.0 and (f) $24.0 \mathrm{wt} \%$. Scale bars $=3.0 \mu \mathrm{m}$.

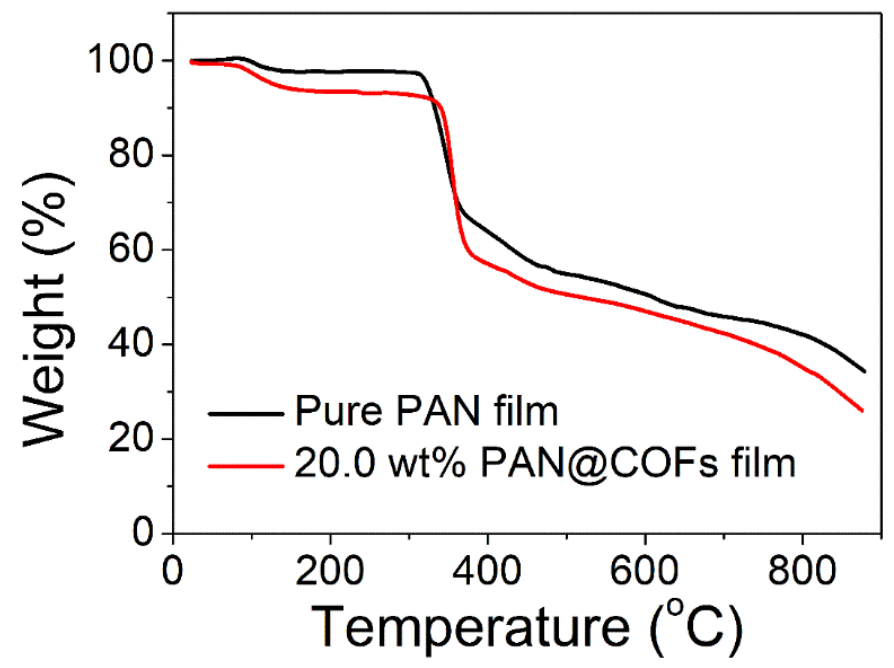

Fig. S14. TG curves of pure PAN film and 20.0wt\% PAN@COF film. 


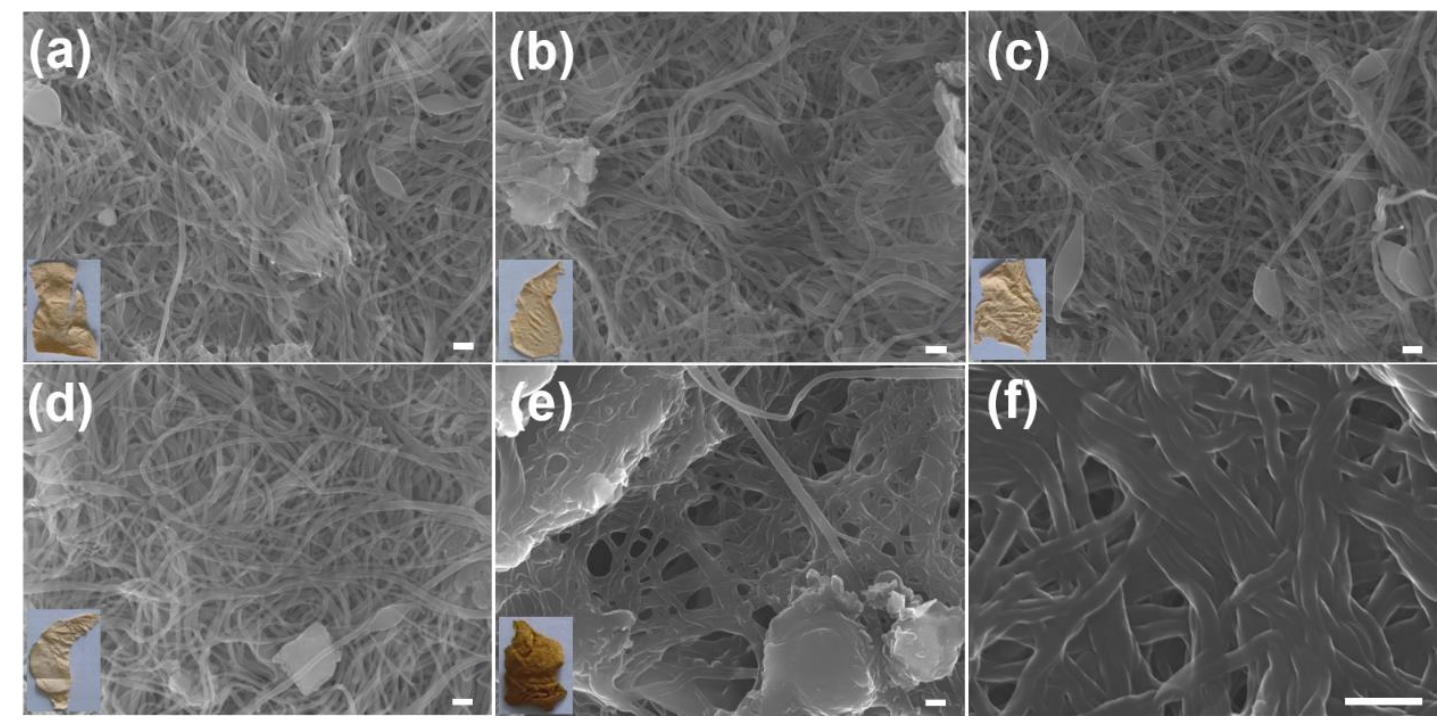

Fig. S15. Photographs and SEM images of the electrospun PAN@COF nanofiber films after treatment with (a) methanol (24 h), (b) methanol (72 h), (c) ethanol (24 h), (d) acetone (24 h) and (e) (f) acetonitrile (24 h). Scale bars $=1.0 \mu \mathrm{m}$.
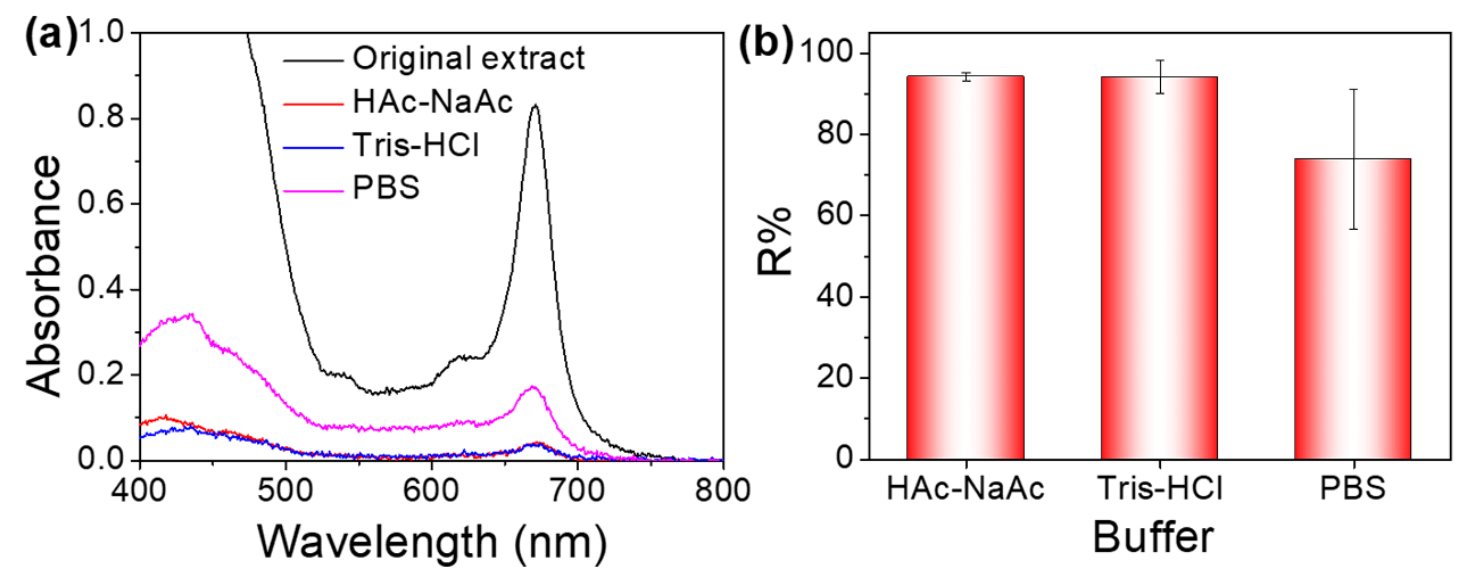

Fig. S16. (a) UV-vis absorption spectra of phytochromes before and after addition of $50 \mathrm{mg} 20 \%$ PAN@COF films. (b) The removal percentage of pigments in different buffers. 

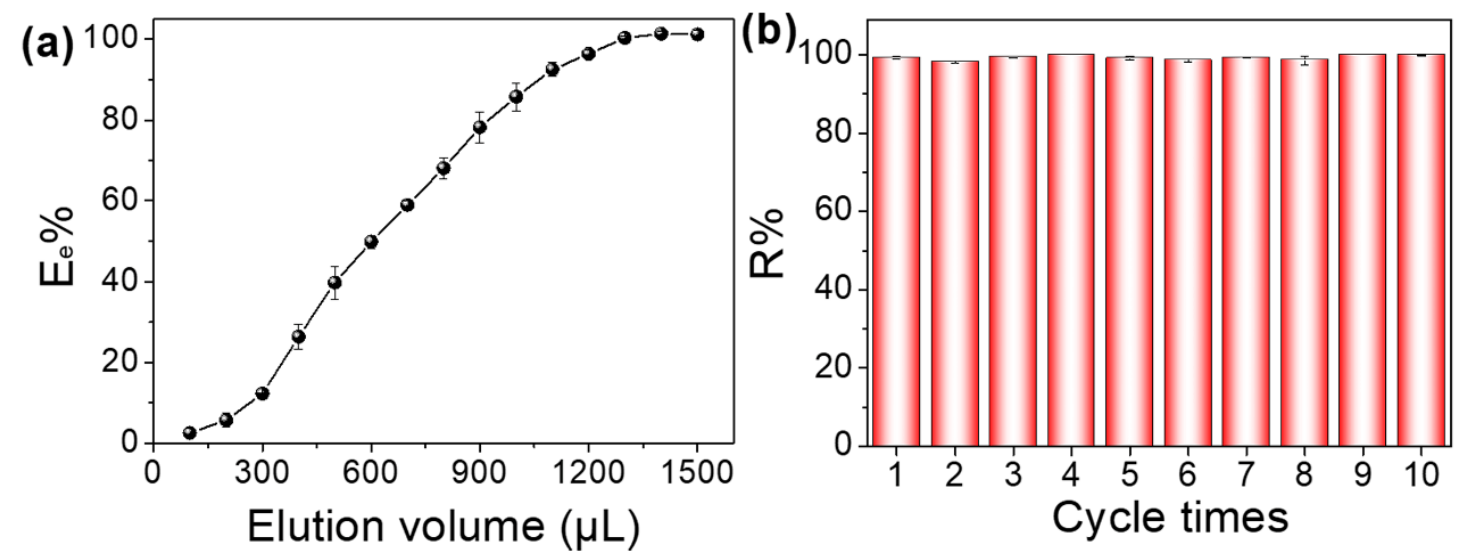

Fig. S17. (a) Optimization of elute volume for $20.0 \mathrm{wt} \%$ PAN@COF film-based filtration mode. (b) Reusability of PAN@COF film for the removal of phytochromes from spinach extracts in filtration mode.
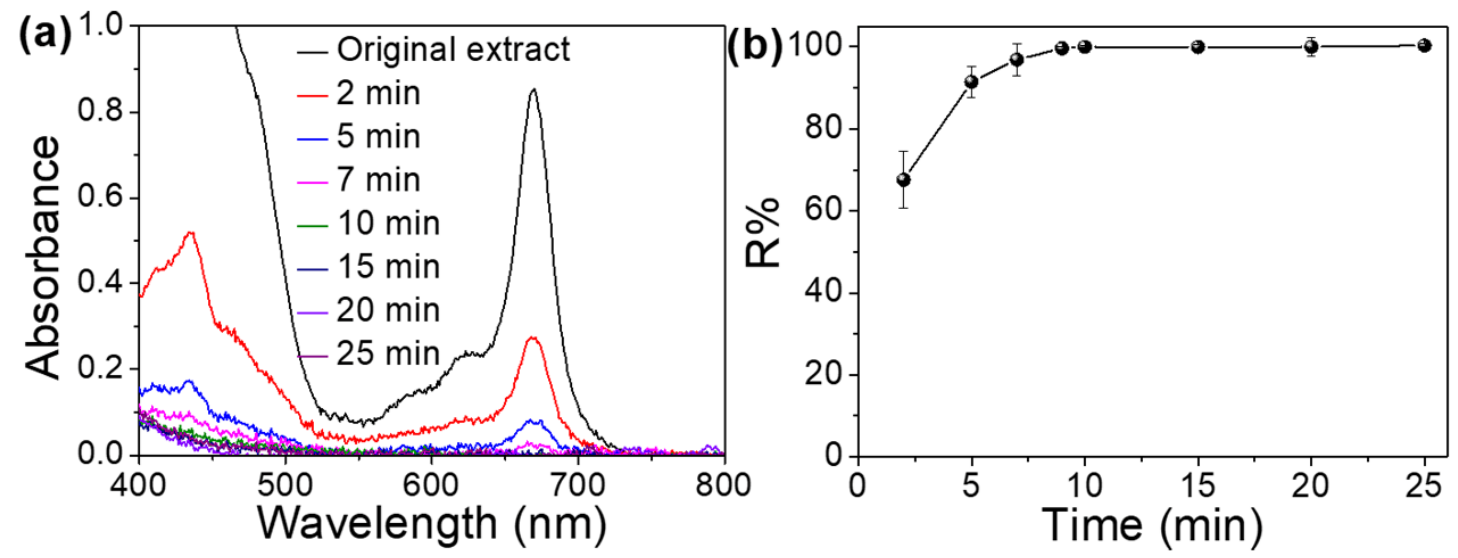

Fig. S18. Optimization of immersion time for phytochrome removal by $30 \mathrm{mg} 20 \mathrm{wt} \%$ PAN@COF film in immersion mode. (a) UV-vis absorption spectra of the phytochrome extracts recorded at different immersion time. (b) Immersion time-dependent phytochrome removal efficiency. 

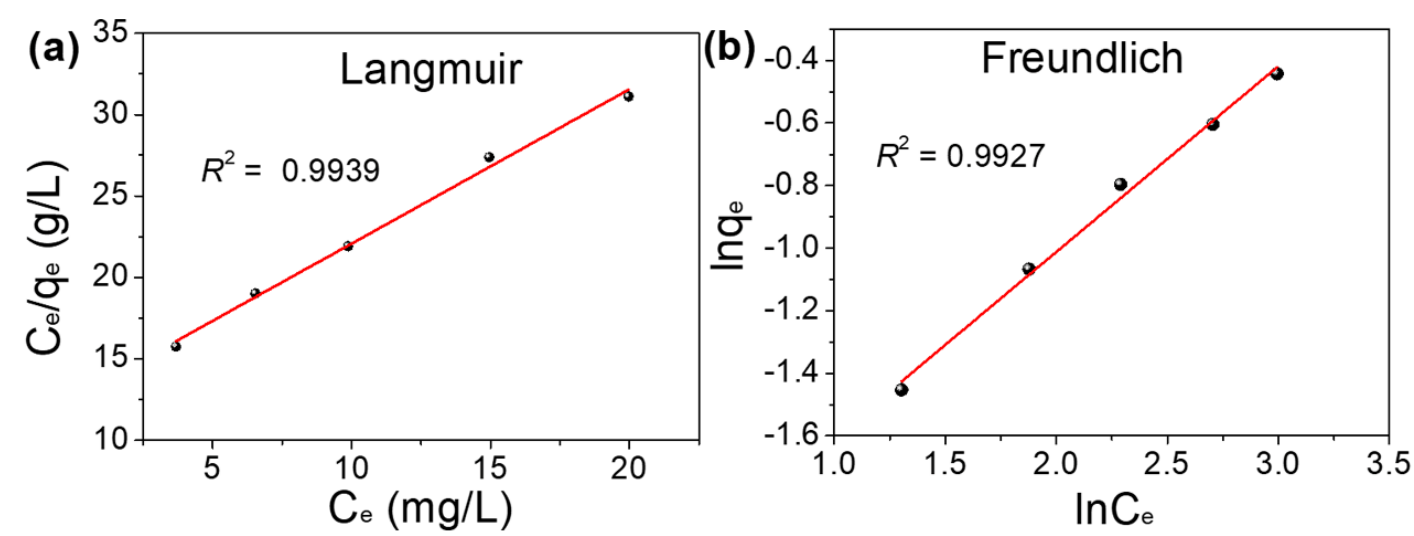

Fig. S19. Static equilibrium absorption isotherms of 20.0 wt $\%$ PAN@COF film fitted by (a) Langmuir and (b) Freundlich models.
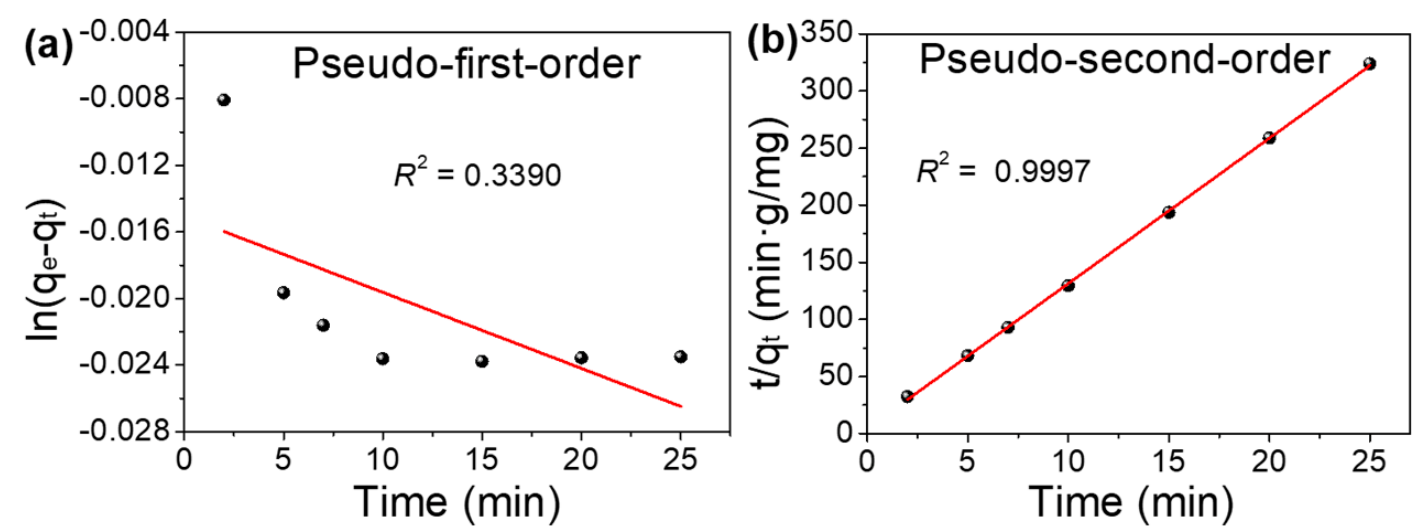

Fig. S20. Phytochrome adsorption kinetics characterization of 20.0 wt\% PAN@COF film by (a) pseudo-first-order and (b) pseudo-second-order kinetic models.
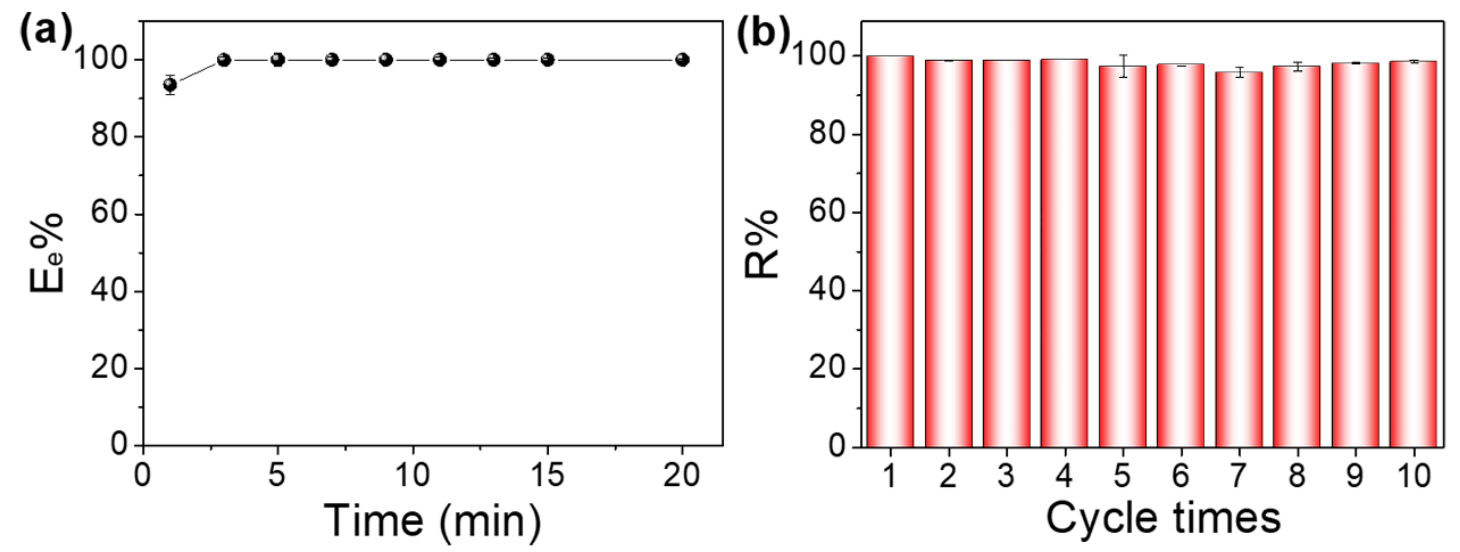

Fig. S21. (a) Optimization of elution time for 20.0 wt\% PAN@COF film-based immersion mode.

(b) Reusability of PAN@COF film for the removal of phytochromes from spinach extracts in immersion mode. 


\section{References}

(1) Concha-meyer, A.; Grandon, S.; Sepulveda, G .; D iaz, R.; A n tonio Yuri, J.; T orres, C. Pesticide residues quantification in frozen fruitand vegetables in Chilean domestic marketusing QuEChER S extraction with ultra-high-performance liquid chromatographyelectrospray ionization 0 rbitrap mass spectrometry. Food Chem.2019,295,64-71.

(2) O liveira, L.G.d.; K urz, M.H.S.; Guimaraes, M . C.M ;; Martins, M . L.; Prestes, O . D .; Zanella, R,; Ribeiro, J. N.d.S.; Goncalves, F. F. Developmentand validation of a method for the analysis of pyrethroid residues in fish using GC-M S. Food Chem. 2019,297 , UNSP 124944.

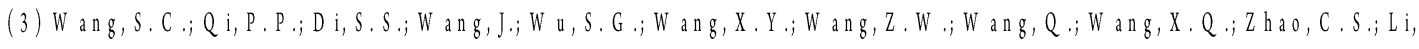
Q., Significantrole of supercritical fluid chromatography - mass spectrometry in im proving the matrix effect and analytical efficiency during multi-pesticides residue analysis of comples chrysanthemum samples. Anal. Chim. Acta 2019, 1074, 108 . 116 .

(4) Zhang, M ; Yang, J.; Geng, X,; Li, Y.; Zha, Z,; Cui, S.; Yang, J. M agnetic adsorbent based on mesoporous silica nan oparticles for magnetic solid phase extraction of pyrethroid pesticides in water sam ples. J. Chromatogr. A2 $019,1598,20$. 29.

(5) Ji, W.H .; Guo, Y.S.; Wang, X.; Lu, X.-F.; Guo, D .-S. A m in o-modified covalent organic framework as solid phase extraction absorbent fordeterm ination of carboxylic acid pesticides in environmental water samples. J. Chromatogr. A2019, $1595,11-18$.

(6) Ji, W ; $S$ un $, R, ; G$ eng, Y .; Liu, W.; W ang, X, Rapid, low tem perature synthesis of m olecularly imp printed covalentorganic frameworks for the highly selective extraction of cyano pyrethroids from plantsam ples. Anal.chim. Acta 2018,1001,179-188.

(7) Perez-Mayan, L.; Rodriguez, I.; Ram il, M.; Kabir, A.; Furton, K. G .; Cela, R. Fabric phase sorptive extraction followed by ultra-performance liquid chromatography-tandem massspectrometry for the determ ination of fungicidesand insecticides in w in e. J. Chromatogr. A2019,1584,13-23.

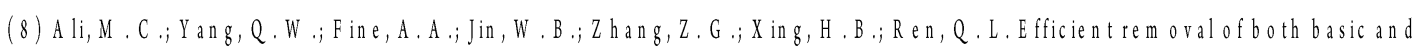
non-basic nitrogen compounds from fuels by deepeutectic solvents. Green Chem.2016,18,157-164.

(9) Neese F. A n A b initio, D F T and sem iem piricalelectron ic structure package, program cersion 2.7, Revision 0 ; Lehrstuhl fuer Theoretische Chem ie Institut fuer Physikalische und Theoretische Chem ie, Universitaet Bonn, Germany (2010). 